\title{
The Use of Ionizing Radiation to Prepare Polymeric Agro-waste Composite for Sandy Soil Application
}

\author{
M. A. Elhady, H. H. Elnahas, G .A. Meligi* and A. H. \\ Ammar** \\ Radiation Research of Polymer Dept., National Centre for \\ Radiation Research and Technology (NCRRT), P. O. Box; 29 \\ Nasr City, Egypt, *Chemistry Dept., Faculty of Science, Ain \\ Shams University and ${ }^{* *}$ Environmental Dept., Egyptian Airports \\ Company.
}

\begin{abstract}
CUPERABSORBENT hydrogel composite (SHC) by radiation $\checkmark$ induced crosslinking of polyacrylamide (PAAM)/ rice straw (RS) composite and hydrophilic membrane system based on polyvinyl alcohol (PVA) for possible applications in agricultural field of sandy soil was studied. The factors affecting the quick and capacity for retaining irrigated water of swelling behaviour of prepared hydrogel composite through hydrophilic membrane system and increasing foaming/ porosity of the SHC were studied.

The mechanism for this is most likely a prevention of irrigated water to pass through sandy particles for a time ranged from 20 to $40 \mathrm{~min}$ for the fluid uptake capacity and swelling of the SHC to take and swelling place without almost any loss of irrigated water. Effect of acid/ alkalinity $(\mathrm{PH})$ and salt concentration were investigation.

Key words: Ionizing radiation, agro-waste, hydrogel, sandy soil.
\end{abstract}

SHC have been used successfully as soil conditioners in the horticulture industry to improve the water retention of soil. The use of hydrogels increase the amount of moisture available in the root zoon, this implies longer intervals between irrigations (Abd El-Mohdy, 2003). Hydrogels are defined as three-dimensional networks of hydrophilic polymer that can absorb and retain a significant amount of water (Juby et al., 2012) with superior hydrophilic properties; hydrogels can hold a large amount of water even under intense pressure. This superiority of hydrogels made them as important materials in a variety of industrial applications as well as in consumer items (Murthy et al., 2006). Recently, some natural resources, e.g. polysaccharides, have been used to produce polymer hydrogels (Ji et al., 2012 and Vakili and Rahneshin, 2013). 
Among numerous polysaccharides, cellulose is the most potential one due to its excellent biodegradability and biocompatibility (Wang and Wang, 2010). Wheat and RS, as by-products of grain crops, is an important biological resource in the crop production system (Talebnia et al., 2010). Wheat and RS contains a high content of cellulose, so they could be chemically modified and used as backbone material for hydrogels (Xie et al., 2011). Radiation polymerization/ crosslinking has many advantages over conventional chemical and photochemical methods. It is a simple environmental friendly additive free process that occurs at room temperature and the degree of cross-linking can be easily controlled by altering the irradiation conditions (Francis et al., 2009). Another advantage of this method is that the resultant product is simultaneously sterilized during their radiation process. Despite these advantages, few studies have been reported on the radiation synthesis of porous hydrogels by using a blowing agent. One of the reasons could be the practical difficulty in producing the bubbles during the course of radiation exposure. Here we report a strategy for the synthesis of water retains system by irradiation method. This method could be extended for the synthesis of fast responding stimulus responsive water retains system which would find more applications (Francis et al., 2009).

\section{Experimental}

\section{Material}

PAAM (M.W. App. 5,000,000-6,000,000) was procured from Merck, Germany. Polyvinyl alcohol with an average M.W. of 125,000 (degree of hydrolysis: 86-89\%) from Kurrary Co., Japan. Sodium borate was obtained from S.D. Fine Chemicals Ltd., Mumbai, India. RS was obtained as a byproduct of rice crop.

\section{Sample Preparation}

To prepare a composite of PAAM/ RS hydrogel mixture 50/ $50 \mathrm{wt} \%, 50 \mathrm{~g}$ PAAM was wet with $10 \mathrm{~g}$ water with a continuous stirring and then $50 \mathrm{~g}$ of RS with length particles ranged from $1-5 \mathrm{~mm}$ was added and mixed well by using a mechanical stirrer at $60 \mathrm{rpm}$ (round per minute) till a homogenous mixture of PAAM/ RS mixture is obtained. The mixture was exposed to $\gamma$-rays for a dose ranged from 10-50 kGy.

Egypt. J. Rad. Sci. Applic., Vol. 28, No. 1-2 (2015) 


\section{Characterization}

\section{Gamma irradiation}

Irradiation was carried out using a cobalt-60 source of $\gamma$-rays manufactured by the Atomic Energy Authority of India, with a dose rate of $2 \mathrm{kGy} / \mathrm{h}$.

\section{Study of water absorption properties}

\section{Measurement of swelling}

In the experiment, $0.20 \mathrm{~g}$ sample was immersed in excess distilled water and kept undisturbed to reach swelling equilibrium. Then swollen samples were filtered through a100-mesh gauze to separate from unabsorbed water and weighted. The water absorption amount $\mathrm{Q}_{\mathrm{eq}}(\mathrm{g} / \mathrm{g})$ was calculated as follows:

$$
\mathrm{Q}_{\mathrm{eq}}=\left(\mathrm{M}_{2}-\mathrm{M}_{1}\right) / \mathrm{M}_{1}
$$

where, $\mathrm{M}_{1}(\mathrm{~g})$ and $\mathrm{M}_{2}(\mathrm{~g})$ are the wt of the dry and swollen sample, respectively. $\mathrm{Q}_{\mathrm{eq}}$ was calculated as grams of water per gram of sample.

\section{Swelling in various $\mathrm{pH}$}

To study the swelling behaviours of hydrogels in solutions with different $\mathrm{pH}$, various $\mathrm{pH}$ solutions were adjusted using $1 \mathrm{~mol} / \mathrm{L} \mathrm{NaOH}$ and $1 \mathrm{~mol} / \mathrm{L} \mathrm{HCl}$ aqueous solutions.

\section{Gel determination}

A dried gel was extract with distilled water for $24 \mathrm{~h}$ at $100^{\circ} \mathrm{C}$ to extract the insoluble parts of gel. The insoluble parts were taken out and washed with hot distilled water for removing the soluble parts and then dried and weighted. This extraction cycle was repeated until the weight became constant. The gel yield in the gel was determined as follows. Gel $(\%)=\left(\mathrm{W}_{\mathrm{e}} / \mathrm{W}_{\mathrm{d}}\right) \mathrm{X} 100$

where, $\mathrm{W}_{\mathrm{e}}$ and $\mathrm{W}_{\mathrm{d}}$ represent the weights of the dry gel and the gelled part after extraction, respectively.

\section{Results and Discussion}

\section{Effect of irradiation dose}

Fig. 1. shows the effect of irradiation dose on water absorbency of a hydrogel of PAAM/ RS mixture in distilled water. The results indicated that the gel swelling in distilled water increase with irradiation dose to reach a 
maximum value at $30 \mathrm{kGy}$. Thereafter, any increase in irradiation dose leads to decrease in hydrogel water absorbency. At low dose the reduction in hydrogel swelling may be due to the high soluble fraction content in copolymer. However, at high doses, the copolymer gel of high crosslinking density was formed. Gel content and crosslinking network density of prepared polymer have a great influence on its swelling character. The higher the gel content, as well as density of crosslinking, the lower the water absorbency. There are many factors affecting the polymer gel content among them, polymer compositions and irradiation doses (Abd El-Mohdy, 2003 and Varshney, 2007).

The irradiation mechanism showed that, as the irradiation dose increases, the number of the small chains increased and the crosslinking density of copolymer system increases. At the same time, the number average molar mass between crosslinks is smaller than at the lower gamma ray doses (Sahiner et al., 1998).

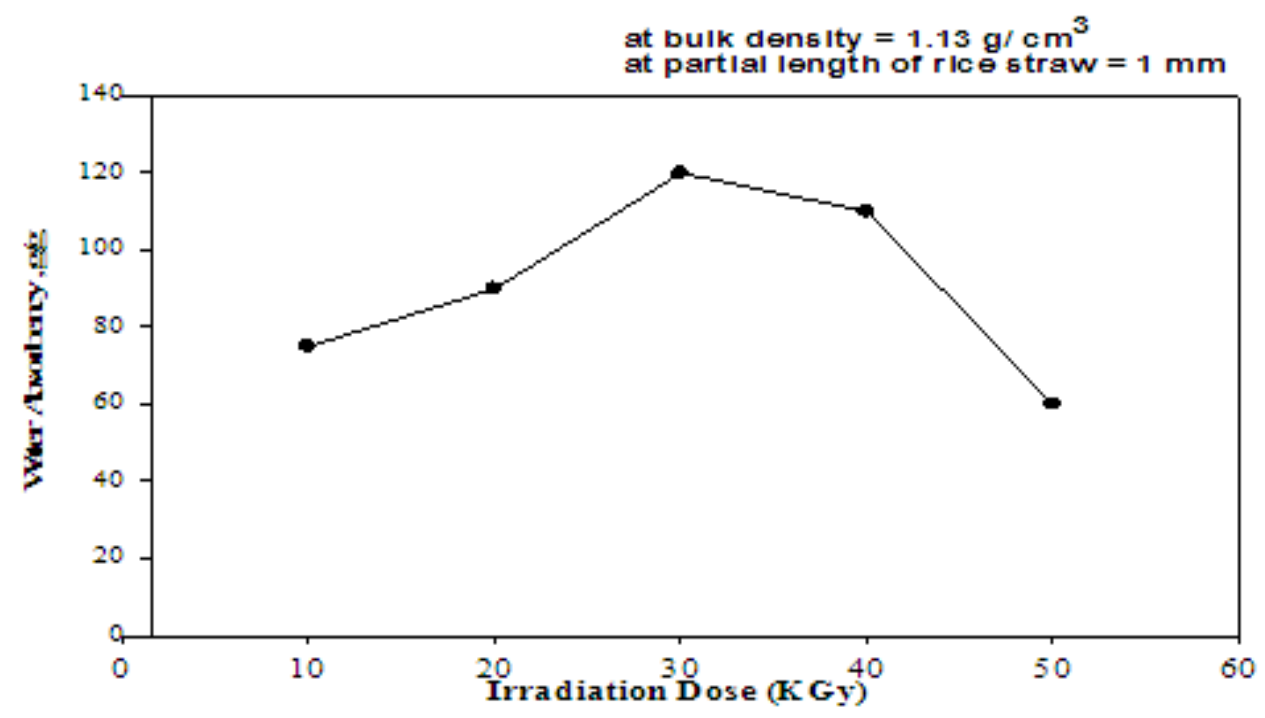

Fig. 1. Effect of irradiation dose on water absorbency of irrigated PAAM/RS mixture $(50 / 50 \%)$.

\section{Effect of bulk density}

Since the pore structure at the surface of hydrogels is through to be an important for fast absorption; the pore structure through the bulk density of the hydrogel of PAAM/ RS mixture is investigated. In Fig. 2. thermal methods was used as blowing agent for obtaining a light bulk density of hydrogel, where at $150^{\circ} \mathrm{C}$ for $10 \mathrm{~min}$ was enough for $0.4 \mathrm{~g} / \mathrm{cm}^{3}$ with an obvious pore structure.

Egypt. J. Rad. Sci. Applic., Vol. 28, No. 1-2 (2015) 
In Fig. 3. The result recorded an increase in water absorbency due to the pore structure as bulk density decreased and decreased in water absorbency as a bulk density increased. Also, it was clear that the swelling rate of thermally foamed hydrogel is faster than that non foamed hydrogel as shown in Fig. 4.

The result indicated that bulk density increase the time absorbency increase due to the porous structures are formed longitudinally by gas forming agents, the gas rises from the bottom to the top of the copolymer surface, resulted in superporous hydrogel of oriented pore structures and fast swelling properties.

The fast swelling of superporous hydrogel in aqueous solution is due to the absorption of water by capillary pressure through interconnected pores (i.e., open channels) which may have diameters in the order of a few hundred micrometres (Kabiri et al ., 2003).

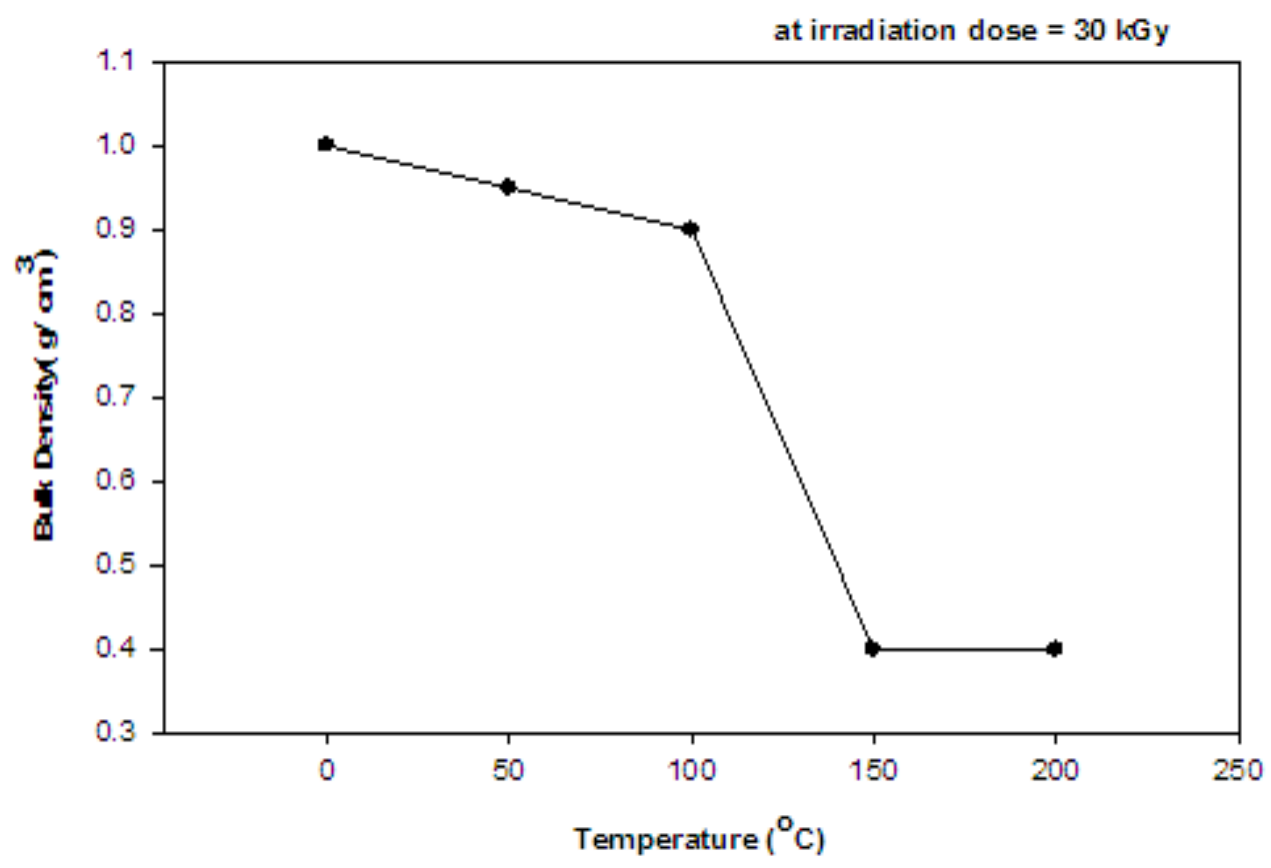

Fig. 2. Effect of temperature on bulk density of irradiated PAAM/RS mixture (50/50\%).

Egypt. J. Rad. Sci. Applic., Vol. 28, No. 1-2 (2015) 


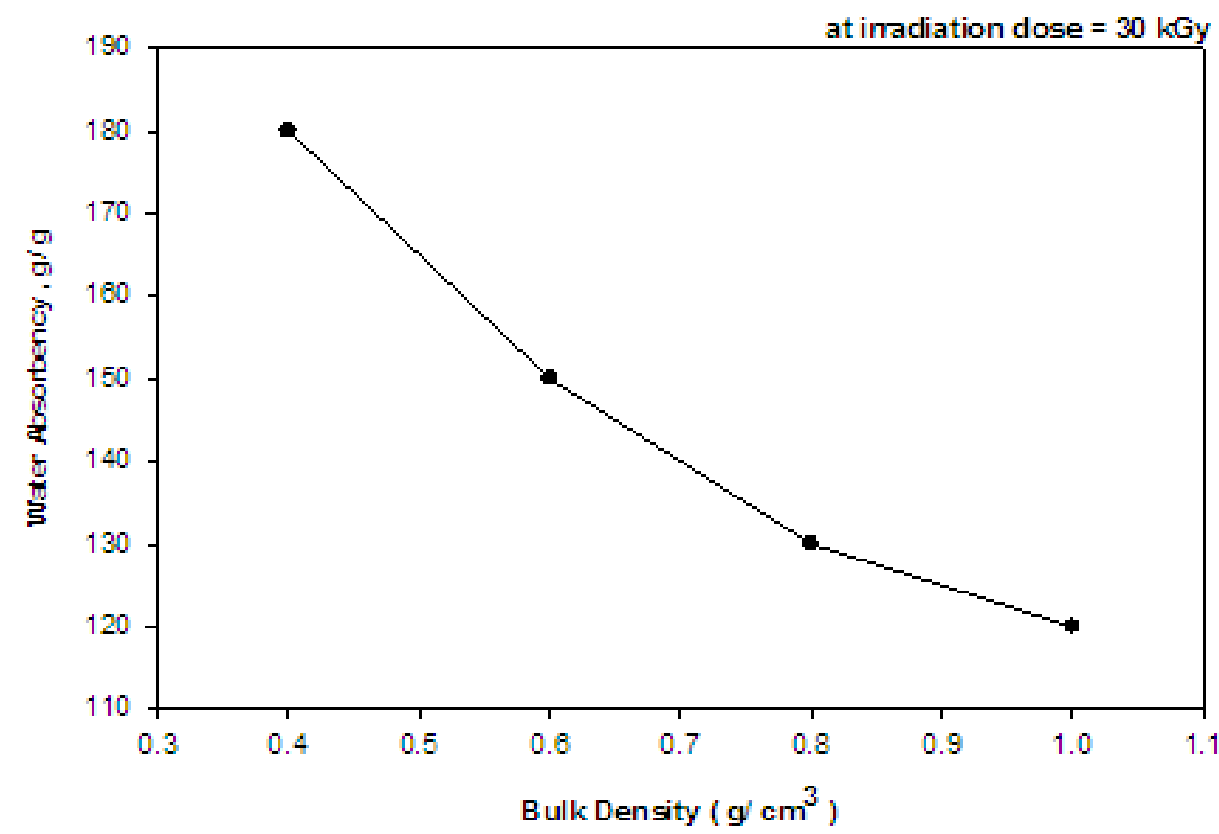

Fig. 3. Effect of bulk density on water absorbency of irradiated PAAM/RS mixture (50/50\%).

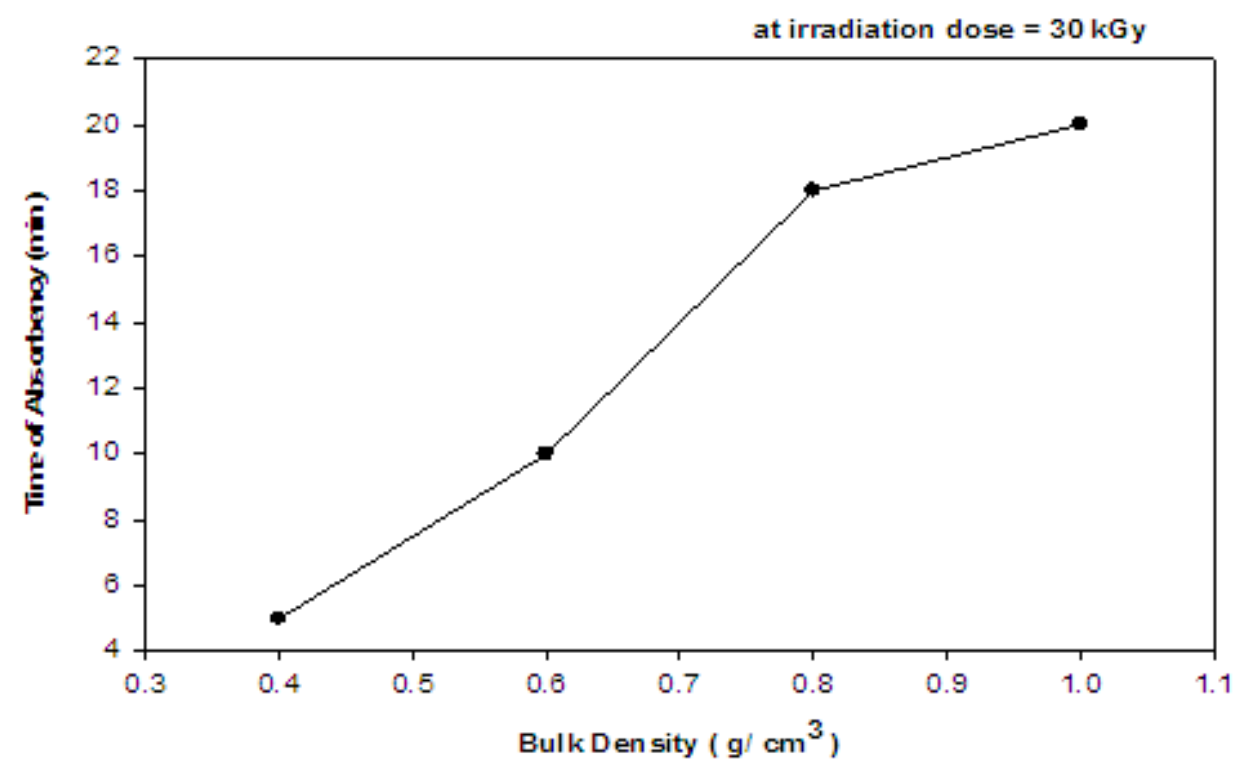

Fig. 4. Effect of bulk density on time of absorbency of irradiated PAAM/RS mixture $(50 / 50 \%)$.

Egypt. J. Rad. Sci. Applic., Vol. 28, No. 1-2 (2015) 


\section{Application on sandy soil}

\section{Important of soil membrane}

The retention of moisture or water, in the soil is fundamental processes upon which all plantations depend. Soil water retention is a basic soil property that is needed for the plant available water, infiltration, drainage, hydraulic conductivity, irrigation, water stress on plants, and solute movement. The large pore spaces in sandy soil prevent water retention. The soil dry out easily and leach precious nutrients past plant roots (Abd El-Mohdy, 2003 and Varshney, 2007). The addition of PVA/ Borax membrane system on the surface of sandy soil as a quick set process gives a full protection for all the irrigated water from losing through the space of sandy particles for a time of $20 \mathrm{~min}$ and this was enough for a complete water absorbency and swelling of the prepared hydrogel of PAAM/ RS mixture (Fig. 5). It was obviously clear through our experimental studies that the addition of PVA/ Borax membrane to the sandy soil prior to addition the hydrogel mixture gives the ideal performance of swelling process and water retention almost irrigation water in which of considered to be more visible and cost save process in sandy soil stabilization for water retention and cultivation.

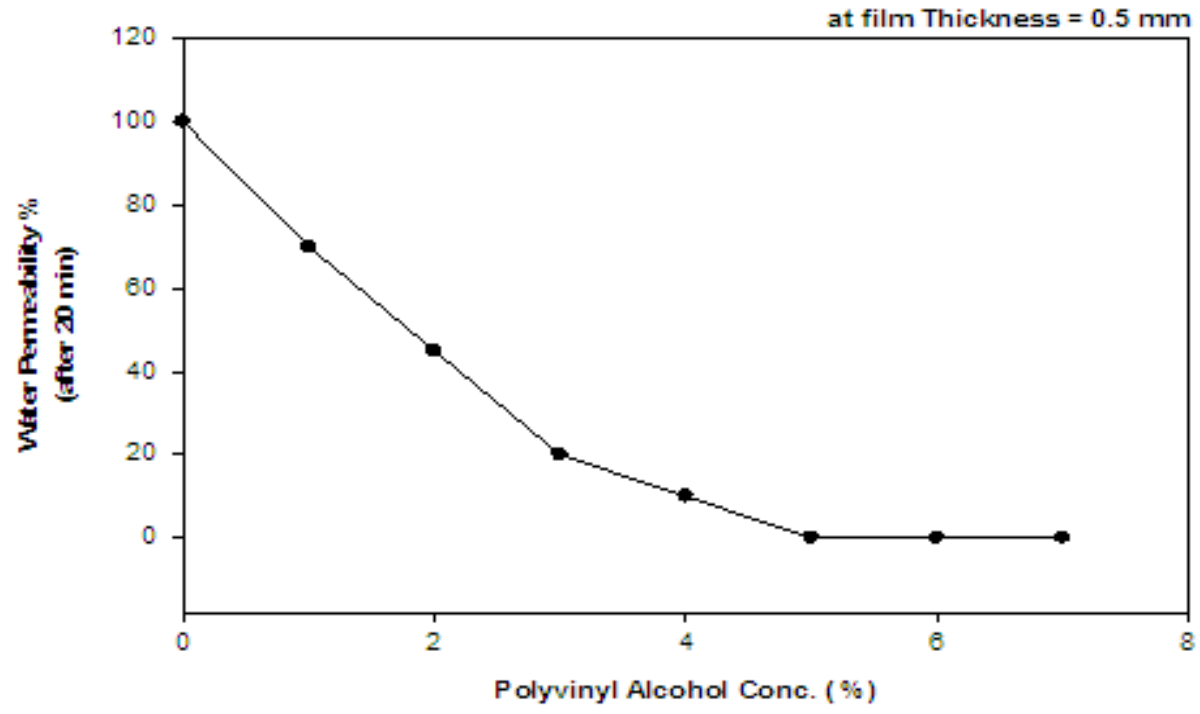

Fig. 5. Effect of polyvinyl alcohol conc. \% on water permeability \% after 20 min through sandy soil.

Egypt. J. Rad. Sci. Applic., Vol. 28, No. 1-2 (2015) 


\section{Effect of particle size on swelling behaviours}

The swelling rate of the small particles was much faster than that of the large ones and the swelling capacity in the equilibrium of the small ones was a little larger than that of the large particles. The reason would be expected from the increase in surface area with decreasing particle size (Omidiana et al., 1999). This space left between the swollen particles which was called free or interstitial volume (Bao et al., 2011), could be used to absorb additional water by a typical capillary action (Lipponen et al., 2012). So the interstitial volume between per unit mass hydrogel was larger, the water absorbency was higher.

Fig. 6. As shown above, a small size of particle size of RS a more capacity of water retention will obtained, where a large amount of surface area of PAAM surrounding the straw particles enhances a positive efficiency of water absorbency process leading to more spaces between swelled hydrogel particles and consequently the area of retained water horizontal increased.

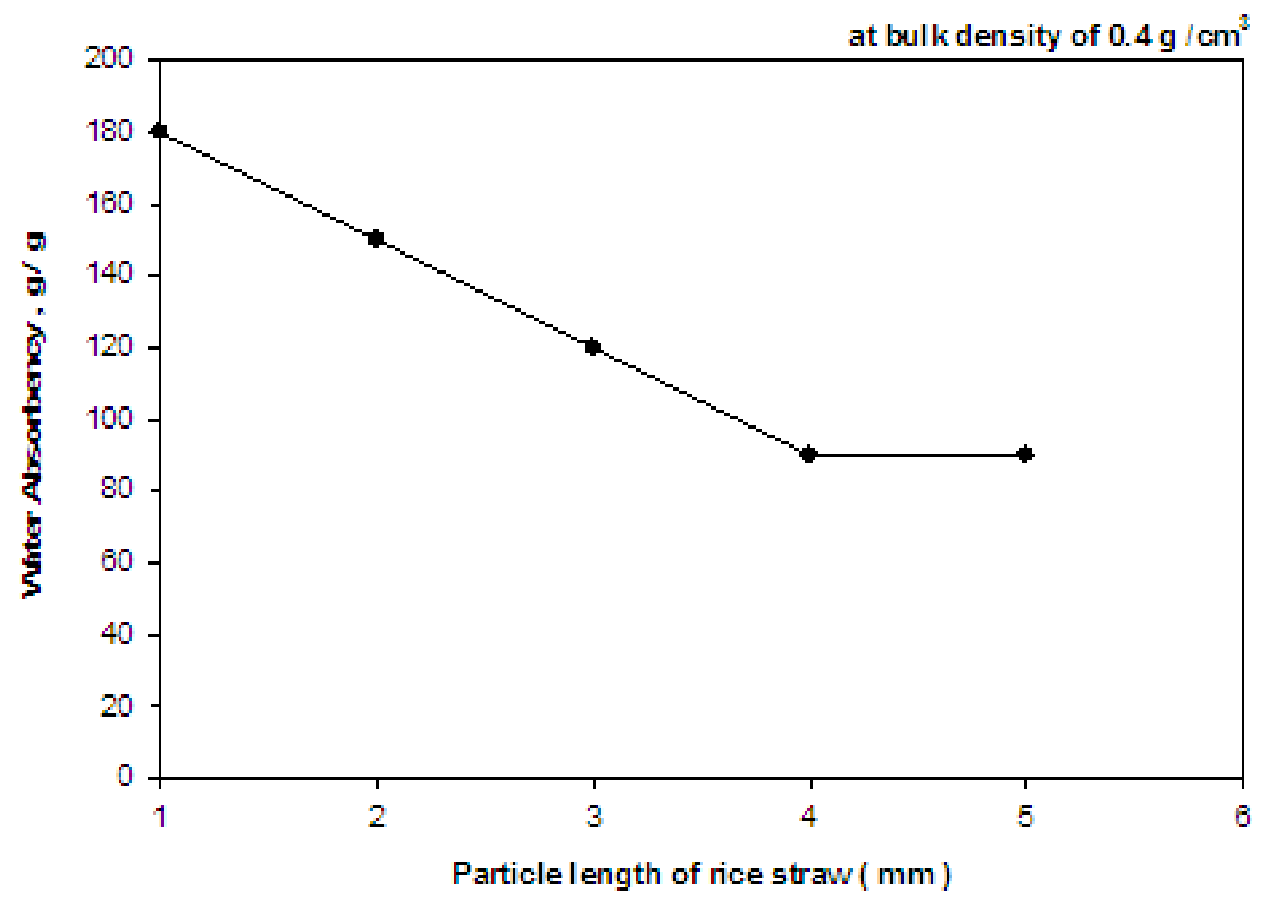

Fig. 6. Effect of particle length of RS on water absorbency of irradiated PAAM/RS mixture $(50 / 50 \%)$.

Egypt. J. Rad. Sci. Applic., Vol. 28, No. 1-2 (2015) 


\section{Measurements of Gel Content}

Gel content increases with increasing irradiation dose at all giving PAAM/ RS mixture that as the irradiation dose increases the primary free radicals and hydrogen atoms formed in the polymers increases. Some of later abstracts are producing secondary free radicals on the polymer chains. Consequently, the interaction and recombination of the free radicals especially the pairs of adjacent radicals is enhanced and resulted in dense crosslink network structure.

The effects of radiation and temperature induced crosslinking on PAAM/ RS mixture depend on the degree of compatibility and the extent of physical and chemical intermolecular interaction between the different types of polymers as shown in Fig. 7\&8. The obtained results assumed that there are intermolecular association between RS and PAAM which may be come from hydrogen bonding, or electrostatic interaction. The intermolecular interaction may be resulted from trapping or entangling of PAAM with the matrix of cellulose part of RS or intertwine between the polymer and cellulose to from helical structure through hydrogen bonding interaction. This interaction may be response for enhancing the extent of crosslinking of the mixture.

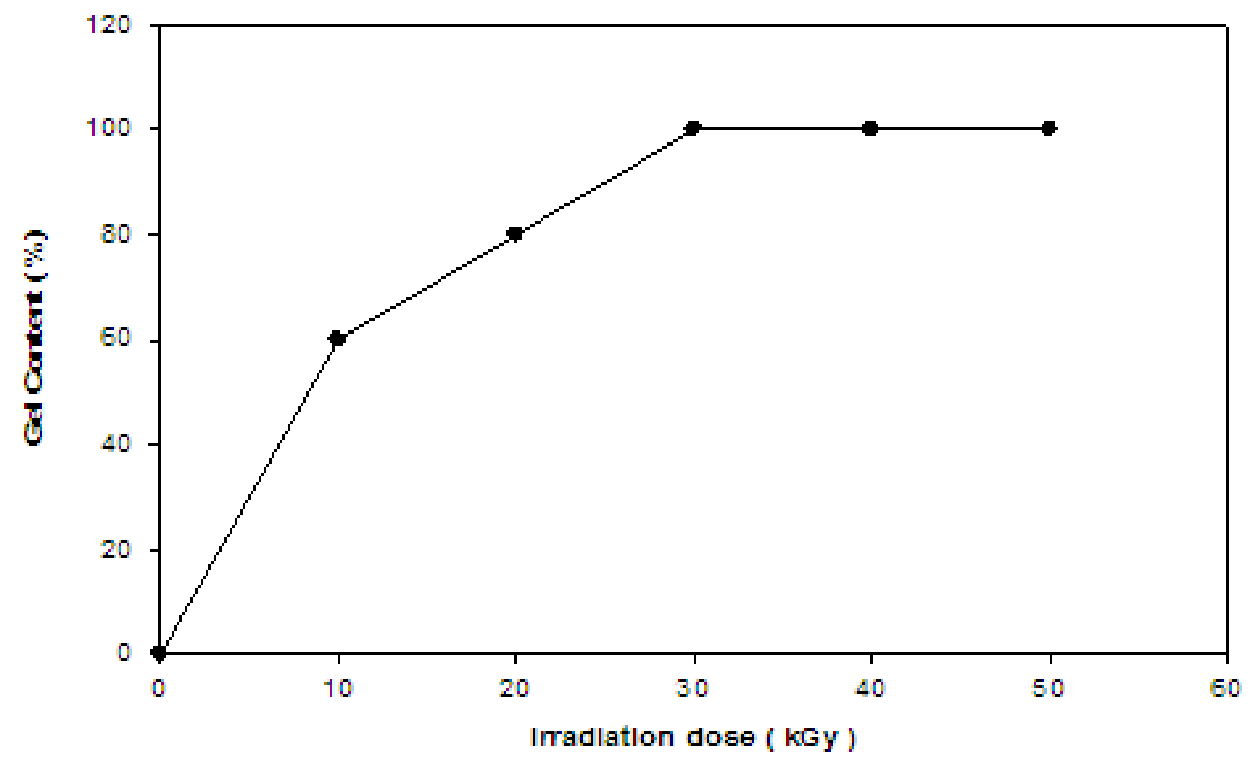

Fig. 7. Effect of irradiation dose on gel content of irradiated PAAM/ RS mixture $(50 / 50 \%)$.

Egypt. J. Rad. Sci. Applic., Vol. 28, No. 1-2 (2015) 


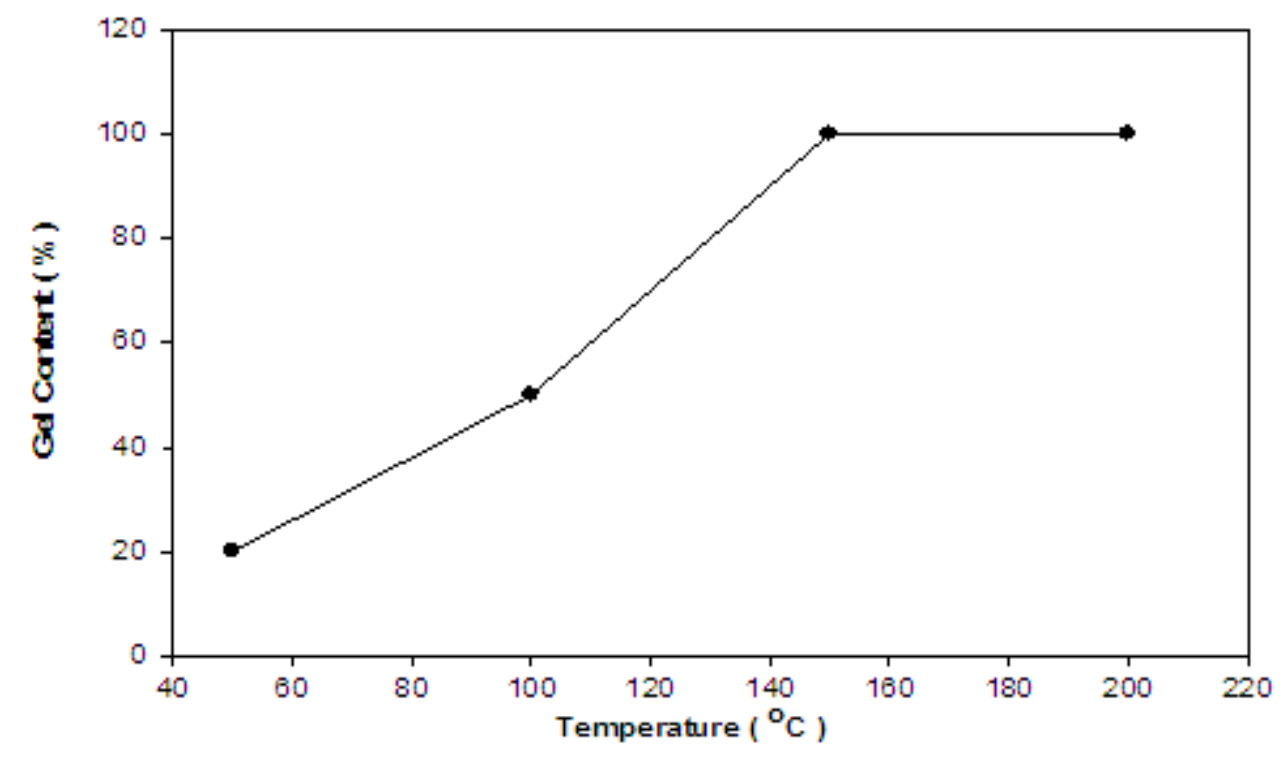

Fig. 8. Effect of temperature on gel content of irradiated PAAM/RS mixture $(50 / 50 \%)$.

\section{Effect of pH on swelling behaviour}

Generally, $\mathrm{pH}$ value is one of the most important parameters affecting the absorption process (Zheng et al., 2011). In order to investigate the influence of $\mathrm{pH}$ values on water absorption was studied at various $\mathrm{pH}$ ranged from 2 to 12 . Because absorbency of hydrogel was strongly affected by ionic strength, no additional ions (through buffer solution) were added to medium for setting $\mathrm{pH}$ As shown in Fig. 9, it can be found that the swelling behaviours of hydrogels were depended on $\mathrm{pH}$, which revealed that they had $\mathrm{pH}$ stimuli-responsive properties. As $\mathrm{pH}$ changing in the range of 2-6, the swelling capacity of hydrogels increased, but decreased at $\mathrm{pH} 8-12$. At lower $\mathrm{pH}$ values $(2<\mathrm{pH}<$ 4 ), the low swelling degree was due to the higher protonation degree of carboxylic groups. While, when $\mathrm{pH}$ value increased to 6 , the carboxylic groups become ionized and the electrostatic repulsion between the molecular chains was predominated, which leads to the network more expanding (Li et al., 2009). At higher $\mathrm{pH}$ values $(8<\mathrm{pH}<12)$, the decreased of swelling capacity can be explained by 'charge screening effect' of excessive $\mathrm{Na}^{+}$in the swelling media (Lanthong et al., 2006).

Egypt. J. Rad. Sci. Applic., Vol. 28, No. 1-2 (2015) 


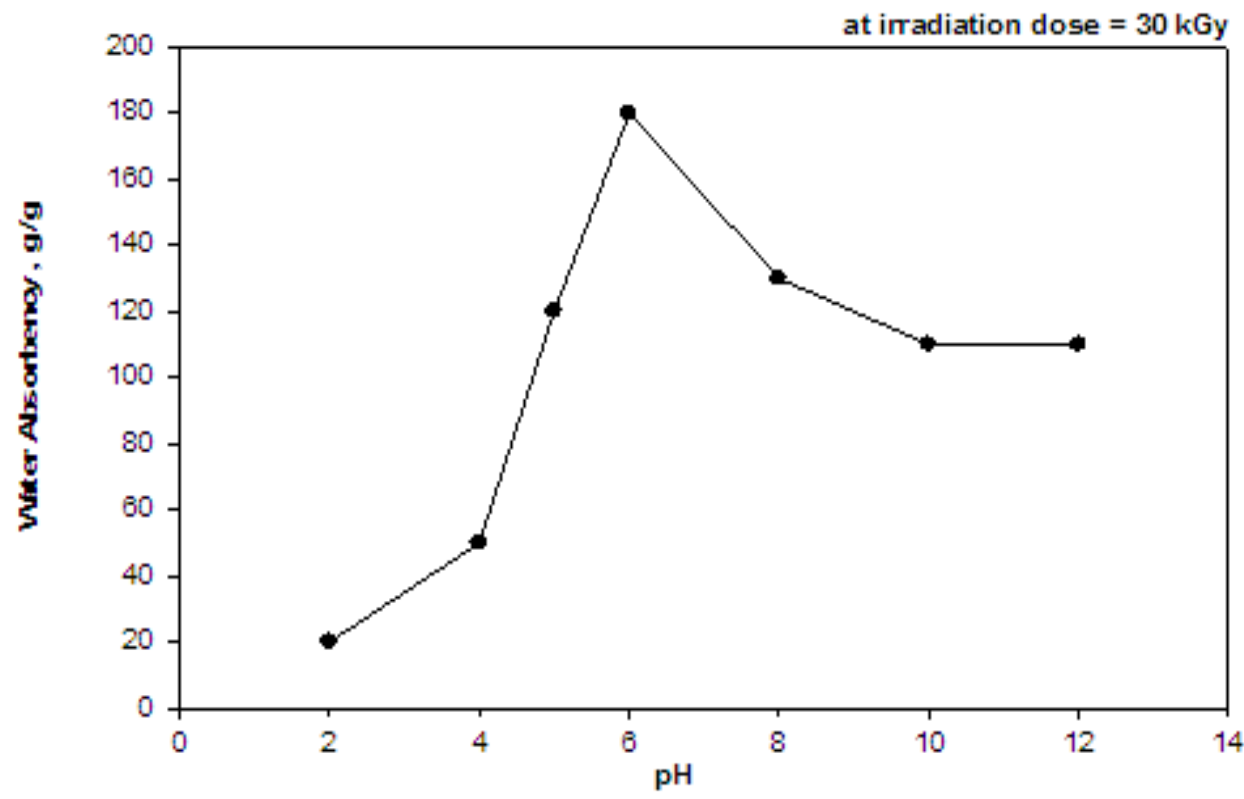

Fig. 9. Effect of $\mathrm{pH}$ on water absorbency of irradiated PAAM/ RS mixture (50/50\%). Application of water retention system

The Following Photographic views showing a complete system for $100 \%$

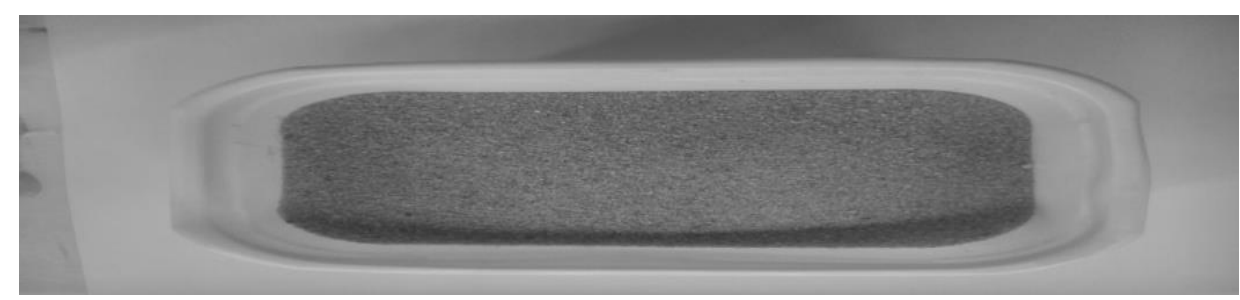

consuming full water irrigation:-

Normal sand surface

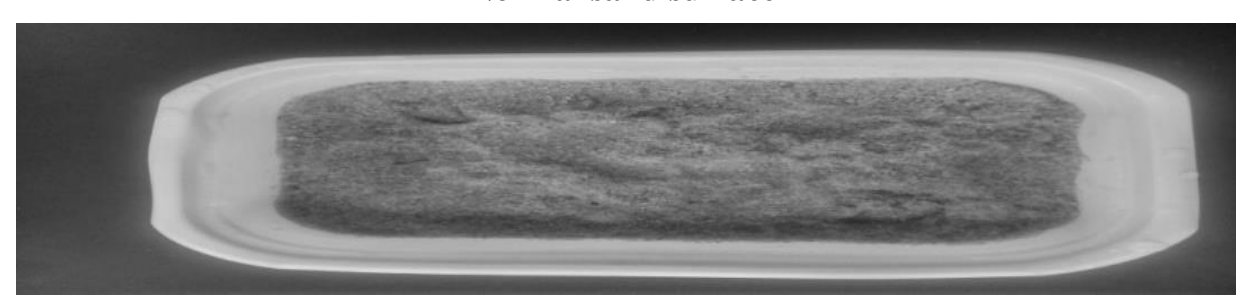

Soil membrane (PVA/ Borax) over sand surface

Egypt. J. Rad. Sci. Applic., Vol. 28, No. 1-2 (2015) 


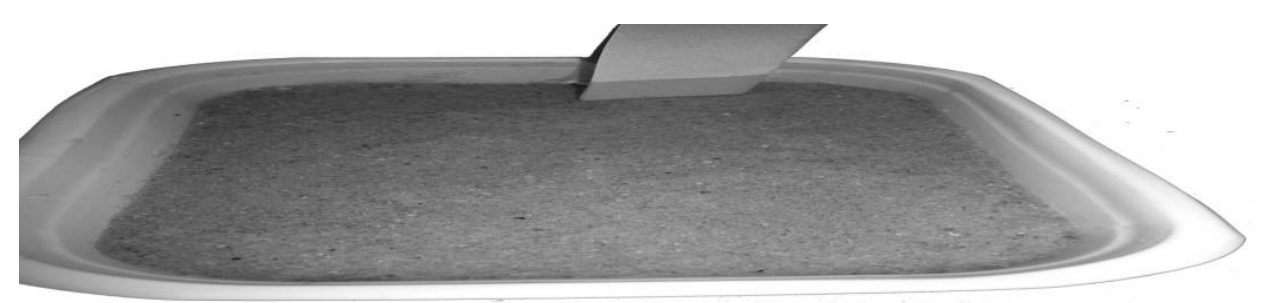

Irrigated water over soil membrane

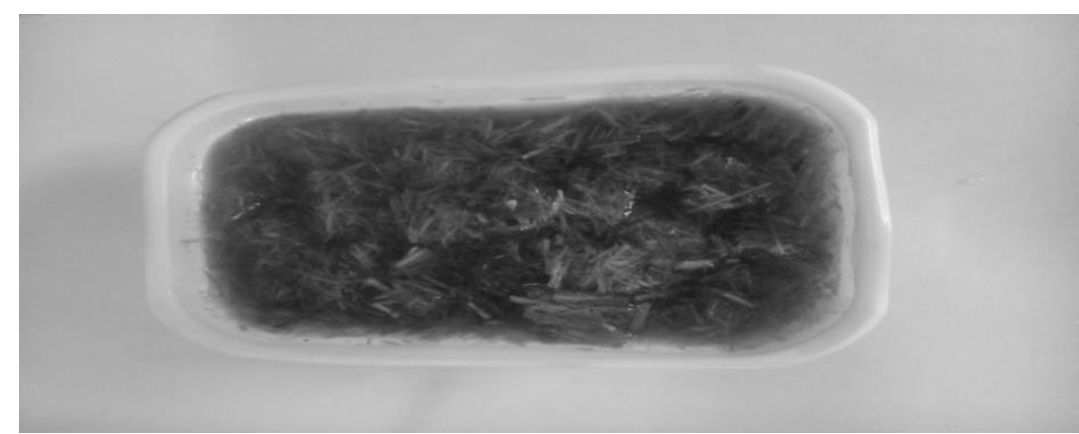

Addition of dry hydrogel of PAAM/ RS mixture and full retention of irrigated water by a hydrogel of PAAM/ RS mixture

\section{Conclusions}

In this study we offer a complete system of soil membrane and amount of super absorbent hydrogel able to retain all the irrigated water without any loss through sandy soil particles. Where, PVA/ Borax combination as a soil surface membrane can help in water retention on sand surface for a time reached to 20 min that can let for hydrogel mixture to absorb all the amount of irrigated water.

The results concluded that the swelling rate of the small particles of RS was much faster than that of the large ones and the swelling capacity in the equilibrium of the small ones was a little larger than that of the large particles. In addition of that the decrease in bulk density of the prepared hydrogel by using thermal process had been achieved an excellent improve for water absorbency in reducing the time and increasing the rate of absorbency.

\section{Acknowledgements}

The authors are grateful for applied support from "AL WADY" private Farm located in EL-Dakhala City, New Village governorate, Egypt.

Egypt. J. Rad. Sci. Applic., Vol. 28, No. 1-2 (2015) 


\section{References}

Abd El-Mohdy, H. L. (2003) Study on characterization and properties of some radiation prepared hydrogels and its possible practical uses. PhD, Faculty of Science, Ain Shams University, Egypt.

Bao, Y., Ma, J. Z. and Li N. (2011) Synthesis and swelling behaviors of sodium carboxymethyl cellulose-g-poly (AA-co-AM-co-AMPS)/MMT superabsorbent hydrogel. Carbohydr. Polym., 84, 76.

Francis, S., Mitra, D., Dhanawade, B.R., Varshney, L., and Sabharwal, S., (2009) Gamma radiation synthesis of rapid swelling superporous polyacrylamide hydrogels. Radiat. Phys. Chem., 78, 951.

Ji, D. Y., Kuo, T. F., Wu, H. D., Yang, J. C. and Lee, S. Y. (2012) A novel injectable chitosan/ polyglutamate polyelectrolyte complex hydrogel with hydroxyapatite for soft tissue augmentation. Carbohydr. Polym., 89, 1123.

Juby, K. A., Dwivedi, C., Kumar, M., Kota, S., Misra, H. S. and Bajaj, P. N. (2012) Silver nano particle-loaded PVA/gum acacia hydrogel: Synthesis, characterization and antibacterial study. Carbohydr. Polym., 89, 906.

Kabiri, K., Omidian, H., Zohuriaan-Mehr, M. J. (2003) Novel approach to highly porous superabsorbent hydrogels: Synergistic effect of porogens on porosity and swelling rate. Polym. Int., 52, 1158.

Keshava Murthy, P. S., Murali Mohan, Y., Sreeramulu, J. and Mohana Raju, K. (2006) Semi-IPNs of starch and poly(acrylamide-co-sodium methacrylate): Preparation, swelling and diffusion characteristics evaluation. React. Funct. Polym., 66, 1482.

Lanthong, P., Nuisin, R. and Kiatkamjornwong, S. (2006) Graft copolymerization, characterization, and degradation of cassava starch-g-acrylamide/ itaconic acid super absorbents. Carbohydr. Polym., 66, 229.

Li, X., Xu, S. M., Wang, J. D., Chen, X. Z. and Feng, S. (2009) Structure and characteri-zation of amphoteric semi-IPN hydrogel based on cationic starch. Carbohydr. Polym., 75, 688.

Lipponen, K., Liu, Y., Stege, P. W., Öörni, K., Kovanen, P. T. and Riekkola, M. (2012) Capillary electro chromatography and quartz crystal microbalance, valuable techniques in the study of heparin-lipoprotein interactions. Anal. Biochem., 424, 71.

Omidiana, H., Hashemi, S. A., Sammes, P. G. and Meldrum, I. (1999) Modified acrylic based superabsorbent polymers (dependence on particle size and salinity). Polymer, 40, 1753.

Sahiner, N., Saraydin, D., Karadag, E. and Guven O. (1998) Swelling and dye adsorption properties of radiation induced $\mathrm{N}$-vinyl-2-pyrrolidone/acrylonitrile hydrogels. Polym. Bull., 41, 371.

Egypt. J. Rad. Sci. Applic., Vol. 28, No. 1-2 (2015) 
Talebnia, F., Karakashev, D. and Angelidaki, I. (2010) Production of bioethanol from wheat straw: An overview on pretreatment, hydrolysis and fermentation. Bioresour. Technol., 101, 4744.

Vakili, M. R. and Rahneshin, N. (2013) Synthesis and characterization of novel stimuliresponsive hydrogels based on starch and 1-aspartic acid. Carbohydr. Polym., 98, 1624.

Varshney, L., (2007) Role of natural polysaccharides in radiation formation of PVAhydrogel wound dressing. Nucl. Instrum. Meth. Phys. Res. B, 255, 343.

Wang, W. B. and Wang, A. Q. (2010) Nanocomposite of carboxymethyl cellulose and attapulgite as a novel $\mathrm{pH}$-sensitive superabsorbent: Synthesis, characterization and properties. Carbohydr. Polym., 82, 83.

Wang, W. B. and Wang, A. Q. (2010) Nanocomposite of carboxymethyl cellulose and attapulgite as a novel $\mathrm{pH}$-sensitive superabsorbent: Synthesis, characterization and properties. Carbohydr. Polym., 82, 83.

Xie, L. H., Liu, M. Z., Ni, B. L., Zhang, X. and Wang, Y. F. (2011) Slow-release nitrogen and boron fertilizer from a functional superabsorbent formulation based on wheatstraw and attapulgite. Chem. Eng. J., 167, 342.

Zhang, J. T., Bhat, R. and Jandt, K. D. (2009) Temperature-sensitive PVA/PNI PAAm semi-IPN hydrogels with enhanced responsive properties. Acta. Biomater., 5, 488.

(Received: 12/07/2015;

accepted: 20/08/2015)

Egypt. J. Rad. Sci. Applic., Vol. 28, No. 1-2 (2015) 
إستخدام الإثعاع المؤين لتحضير خليط من بوليمر و مخلفات

زراعية لتطبيقها فى مجال التربة التبونية الرملية

محمد احمد الهادى ، و حسين حسين النحساس ، و جمـال عبد العزيز مليجى* ،

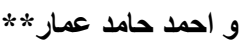

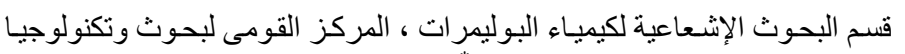

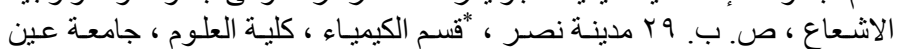

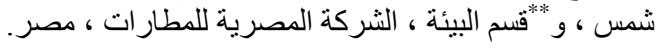

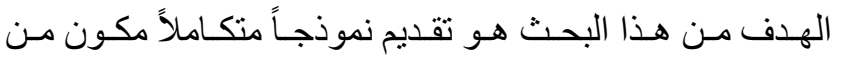

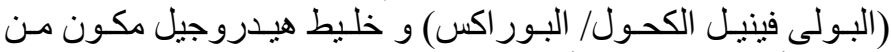

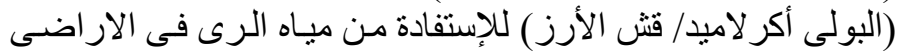

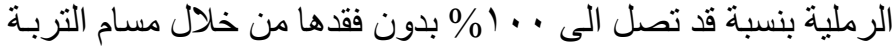

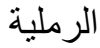

$$
\text { وذللك بإستخدام الخطوات الآتية : }
$$

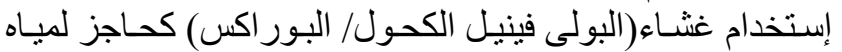

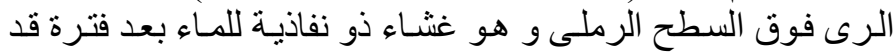

تصل الى • ب الى دقيقة.

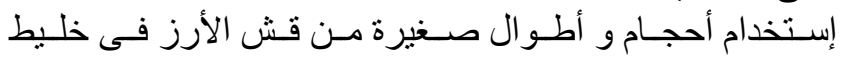

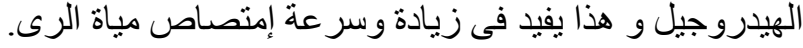

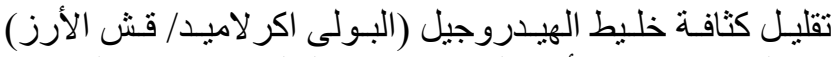

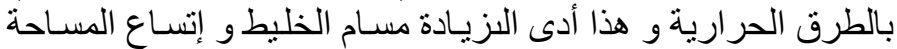

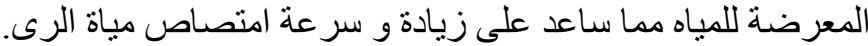

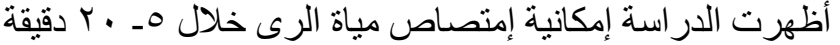

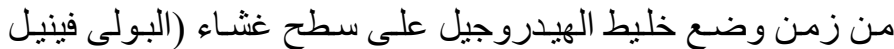

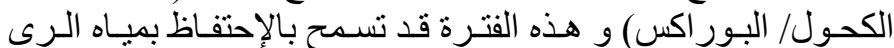

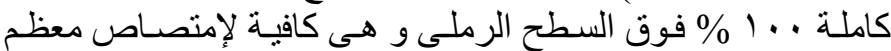

مياه الرى دون فقد من خلال مسام التربة الرملية

Egypt. J. Rad. Sci. Applic., Vol. 28, No. 1-2 (2015) 